\title{
Characterization of Phosphide Platelets in Eutectic Sand Cast Cu-Sn-P Alloy
}

\author{
L. O. Mudashiru1, T. M. Azeez ${ }^{2}$, S. O. Afolabi'2, I. A. Babatunde1 \\ ${ }^{1}$ Department of Mechanical Engineering, Ladoke Akintola University of Technology, Ogbomosho, Nigeria \\ ${ }^{2}$ Department of Mechanical and Mechatronics Engineering, Afe Babalola University, Ado Ekiti, Nigeria \\ Email: lomudashiru@lautech.edu.ng, mriibs4real@yahoo.com, afowolesam@yahoo.com, \\ mrbababuhafizor@gmail.com
}

Received 25 March 2015; accepted 29 June 2015; published 2 July 2015

Copyright (C) 2015 by authors and Scientific Research Publishing Inc.

This work is licensed under the Creative Commons Attribution International License (CC BY). http://creativecommons.org/licenses/by/4.0/

(C) (i) Open Access

\begin{abstract}
A procedure for evaluating the degree of spheroidization of phosphide platelets in cast $\mathrm{Cu}-4 \% \mathrm{Sn}$ 5\%P alloys using fractal analysis was investigated. The specimens were obtained by melting copper and tin in an improvised clay mould raised to a temperature of $1850^{\circ} \mathrm{C} \pm 20^{\circ} \mathrm{C}$, holding for a period of 10 minutes to 1 hour to modify the aspect ratio of the phosphide platelets. It was found that these platelets have the tendency to change their shape from being spherical to more Euclidian shapes as time elapses. It was found that the inter-platelets distances are approximately equal with time. This effect was more pronounced in samples with high holding time.
\end{abstract}

\section{Keywords}

Spheroidization, Clay Mould, Platelets, Euclidian Shapes

\section{Introduction}

Copper-tin peritectic alloys, also known as tin-bronzes, are widely used in many industrial applications such as boiler feed waters, polluted in-shore waters and acidic waters handling [1] [2]. Tin-bronzes especially those with higher tin contents are also used in wear resistant applications as an alternative to phosphor-bronzes. Due to their remarkable properties, i.e. high strength, high thermal conductivity, good wear resistance and machinability, these alloys are also well adapted for the automotive and electronic industries. [3] [4] affirmed that phosphorus-bronzes are prime candidates for high heat flux applications in fusion energy systems. High heat flux is a major challenge for various fusion devices because of the extremely high energy density required in controlled thermonuclear fusion.

Phosphor bronze has been widely used in connectors and relay contacts thanks to its low young modulus and 
high strength. [5] revealed that phosphor bronze generally degrades in bending workability when heavily worked for work hardening. To improve such characteristics, Furukawa Electric developed F5218 and F5248 alloys, new versions of phosphor bronze for springs with smaller grain size, provided with improved strength and bending workability. [6] examined the dynamic recrystallization (DRX) behavior in a newly developed Cu-Sn-P alloy for high strength copper.

The technology of copper alloy founding has advanced considerably in recent years and castings are produced to a high degree of integrity to fulfill many critical applications where inspection requirements are particularly onerous. Conventional phosphor bronzes are a compromise, with optimum additions of phosphorus and tin to provide high strength as possible coupled with a relatively high thermal and electrical conductivity [7]-[9]. In this study, fractal analysis was used to characterize the phosphide platelets in cast Cu-Sn-P alloy.

\section{Materials and Method}

\subsection{Materials}

Tin bronzes may conveniently be divided into two groups: low-tin bronzes and high-tin bronzes. Low-tin bronzes are those in which the tin content is less than $17 \%$. This is the maximum theoretical limit of the solubility of tin in the copper-rich solid solution. In practice, the usual limit of solid solution is nearer to 14\% [10], although it is rare to find a bronze with this tin content in a homogeneous single phase. In this study, a low tin-bronze alloy was selected for the experimental work having a nominal composition Cu-4\%Sn-5\%P.

\subsection{Casting Technique}

Clay is one of the most widely used ceramic raw materials which are found naturally in great abundance, often used as mined without any further processing. When mixed in the appropriate proportions, clay and water form a plastic mass that is very amenable to shaping [11]. The formed piece is dried to remove moisture and fired at an elevated temperature to improve its mechanical strength. In this study, an improvised clay molded vacuum crucible pots of $5 \mathrm{~mm}$ thickness was employed. The crucible pots consist of the melting and the casting sections. Each sample was charged in each of the crucible pots and sun-dried for 72 hours.

Preliminary study conducted revealed that the crucible pot attains a temperature of $1850^{\circ} \mathrm{C}$ before adequate heat could be transferred to melt the sample. With this knowledge, each sample in the crucible pot was heated to a temperature of $1850^{\circ} \mathrm{C} \pm 20^{\circ} \mathrm{C}$, after which the cast alloys in rod forms were obtained. It was found that the residual red elementary phosphorus may be sufficient to be present as compound of phosphide which may have certain effect on the properties of the material depending on the geometries. In this study, each sample was raised to a temperature of $1850^{\circ} \mathrm{C} \pm 20^{\circ} \mathrm{C}$, homogenized for $10,20,30,40,50$ minutes and 1 hour respectively, cast in clay mould and normalized.

\subsection{Microstructural Analysis}

An optical metallurgical microscope XJL-17 model with magnification $10 \times 10$ was used to obtain the micrograph of the samples Figure 1 . The analysis captured a square shape of approximately $3 \mathrm{~mm} \times 3 \mathrm{~mm}$ of the specimen. All samples were prepared by grinding and polished with silicon carbide gel in the order 220, 320,400 and 600 grit sizes. Optical examination was performed prior to etching with $2 \%$ alcoholic ferric chloride solution, to identify inclusions and other casting defects.

\subsection{Fractal Analysis of Phosphide Platelets Characterization}

Fractal geometry was firstly developed by [12]. Its principle is universal in any measurement and has been previously used by many researchers to numerically describe complex microstructures including graphite flakes, nodules and pores [13]-[17]. The mathematical basis for measuring chaotic objects with the power law is adopted in this work. The basic equation is as follows:

$$
P=P_{e} \delta^{D-1} \quad\left(1<D<2 \text { and } \delta_{m}<\delta<\delta_{M}\right)
$$

where " $P_{e}$ " is the measured perimeter, " $P$ " is the true perimeter, " $\delta$ " is the yardstick, " $\delta_{m}$ " and " $\delta_{M}$ " are the upper and lower limits respectively for any shape and “ $D$ ” is defined as the fractal dimension. The fractal dimension " $D$ ” 


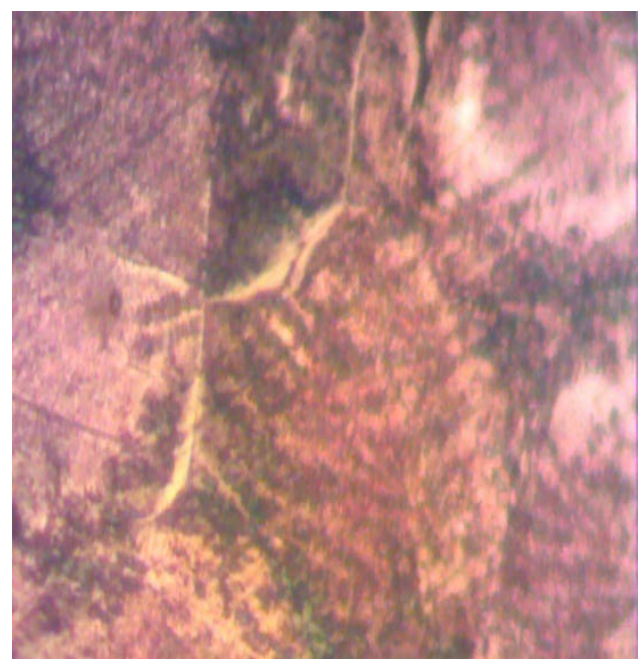

(a)

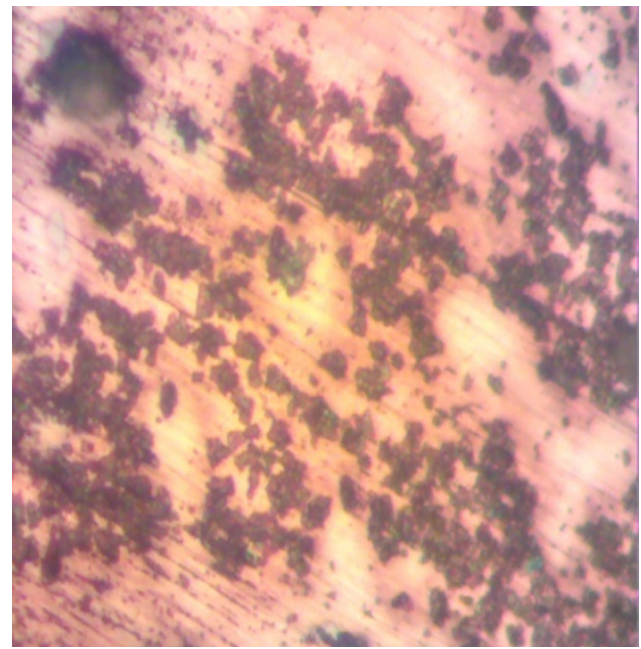

(c)

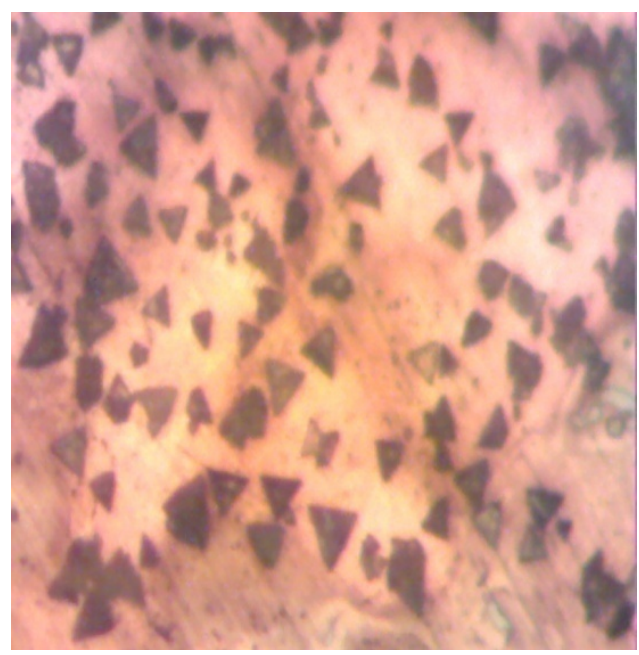

(e)

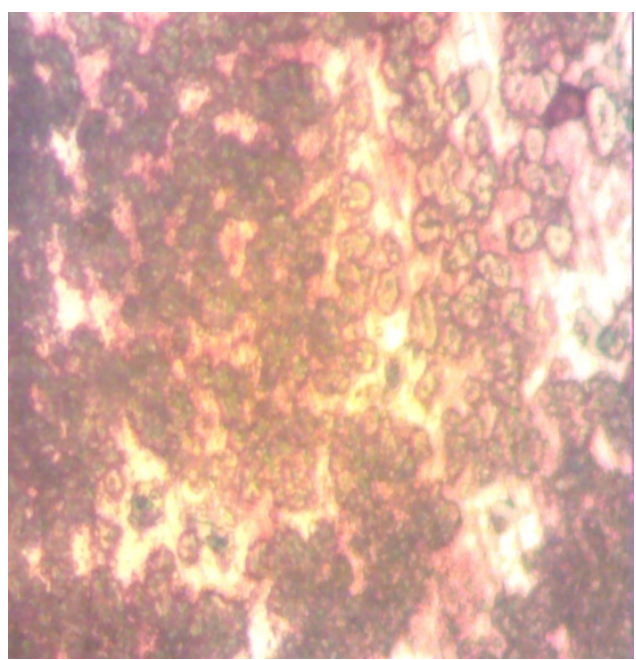

(b)

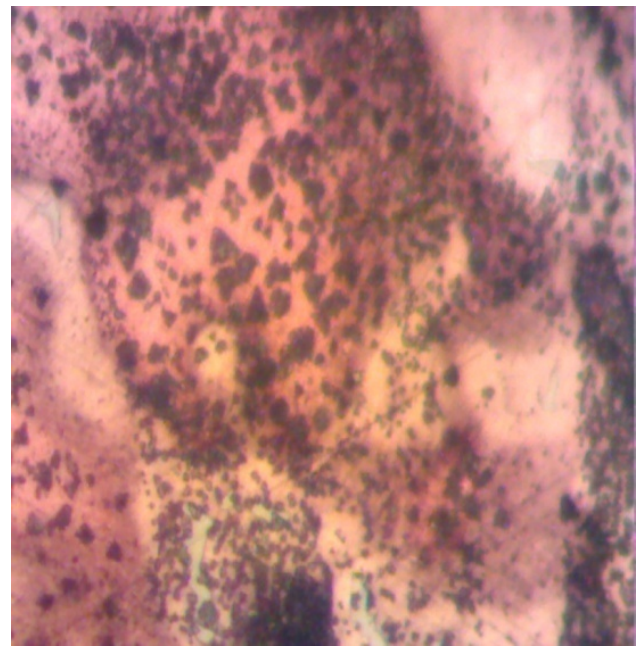

(d)

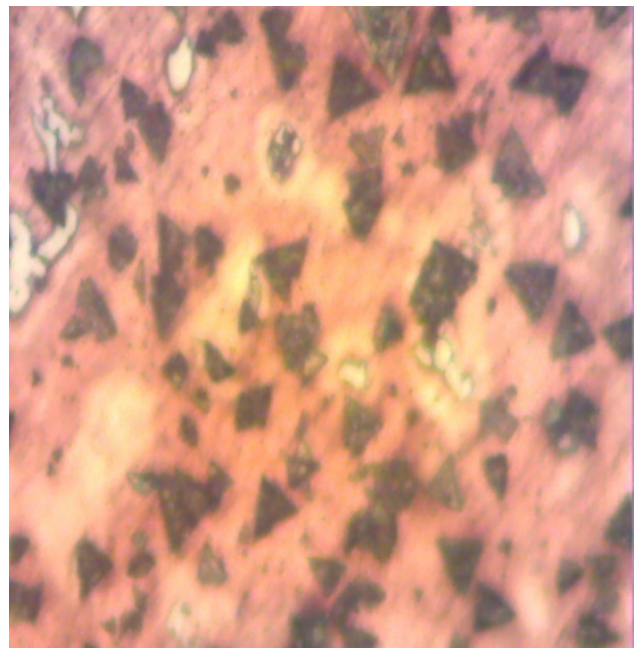

(f)

Figure 1. Micrographs of the Cu-4\%Sn-5\%P homogenized for (a) 10 mins; (b) 20 mins; (c) 30 mins; (d) 40 mins; (e) 50 mins and (f) 1 hour respectively. 
describe the complexity of the contour of an object which can be more practically called roughness. Sphericity " $\beta$ ", on the other hand is used with fractal dimension " $D$ ", to describe the shape of the platelets formed [4] and [13]. It can be expressed as:

$$
\beta=4 \pi A_{T} / P^{2} \quad(0<\beta<1 \text { and } 1<D<2)
$$

From the above two equations:

$$
\beta=\left(4 \pi A_{T} / P^{2}\right) \delta^{2(1-D)} \quad(0<\beta<1 \text { and } 1<D<2)
$$

where " $A_{T}$ " is the total platelets area. When $\beta=1$ and $D=1$, a perfect circular shape is formed by the platelets in the microstructure. As $\beta$ decreases, the shapes become more elongated showing a departure from perfect sphere.

In this work, an interactive Matlab program was developed to obtain the numerical values of the fractal dimension " $D$ " and the sphericity " $\beta$ ". To develop the program the box counting method was used with a counter incorporated into the program and the small boxes or pixels occupied by the platelets outlines were counted. In all, four pixels $(2 \times 2$ pixels, $4 \times 4$ pixels, $8 \times 8$ pixels and $16 \times 16$ pixels $)$ and four grid sizes $(200 \times 200,100 \times$ $100,50 \times 50$ and $25 \times 25$ ) were selected. The selections were made for better resolution and to obtain accurate results. The spatial point pattern method (Figure 2) and the platelets distribution map (Figure 3) [12] were used to describe the patterns displayed by the platelets after the addition of different percentage of phosphorus to the molten $\mathrm{Cu}$. The platelets distribution map can further be used to identify the shapes of the platelets and their dispersion from regular shapes.

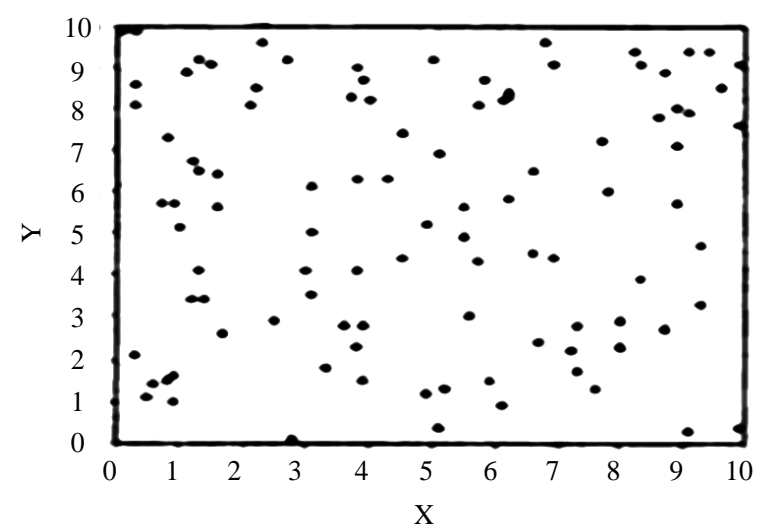

(a)

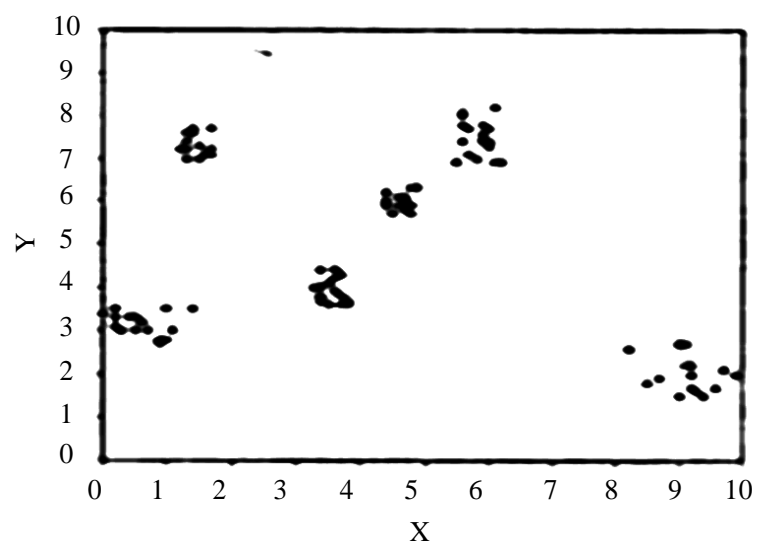

(c)

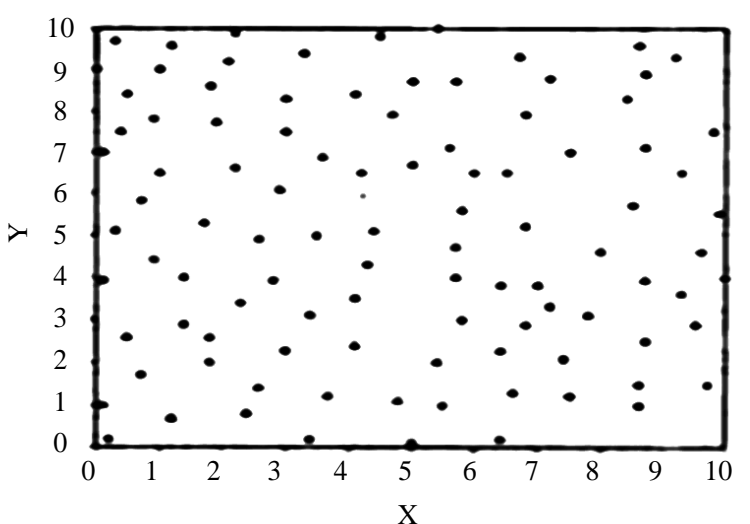

(b)

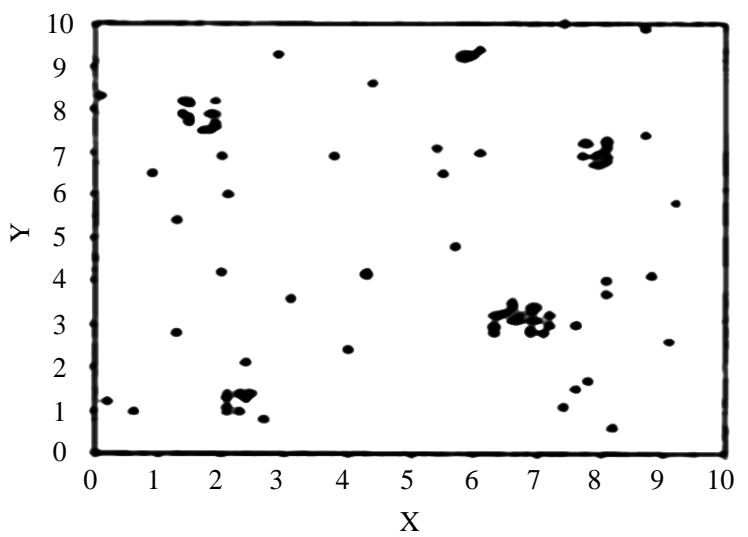

(d)

Figure 2. The four common types of spatial point patterns (a) random; (b) regular; (c) clustered; (d) clustered superimposed on random background. 


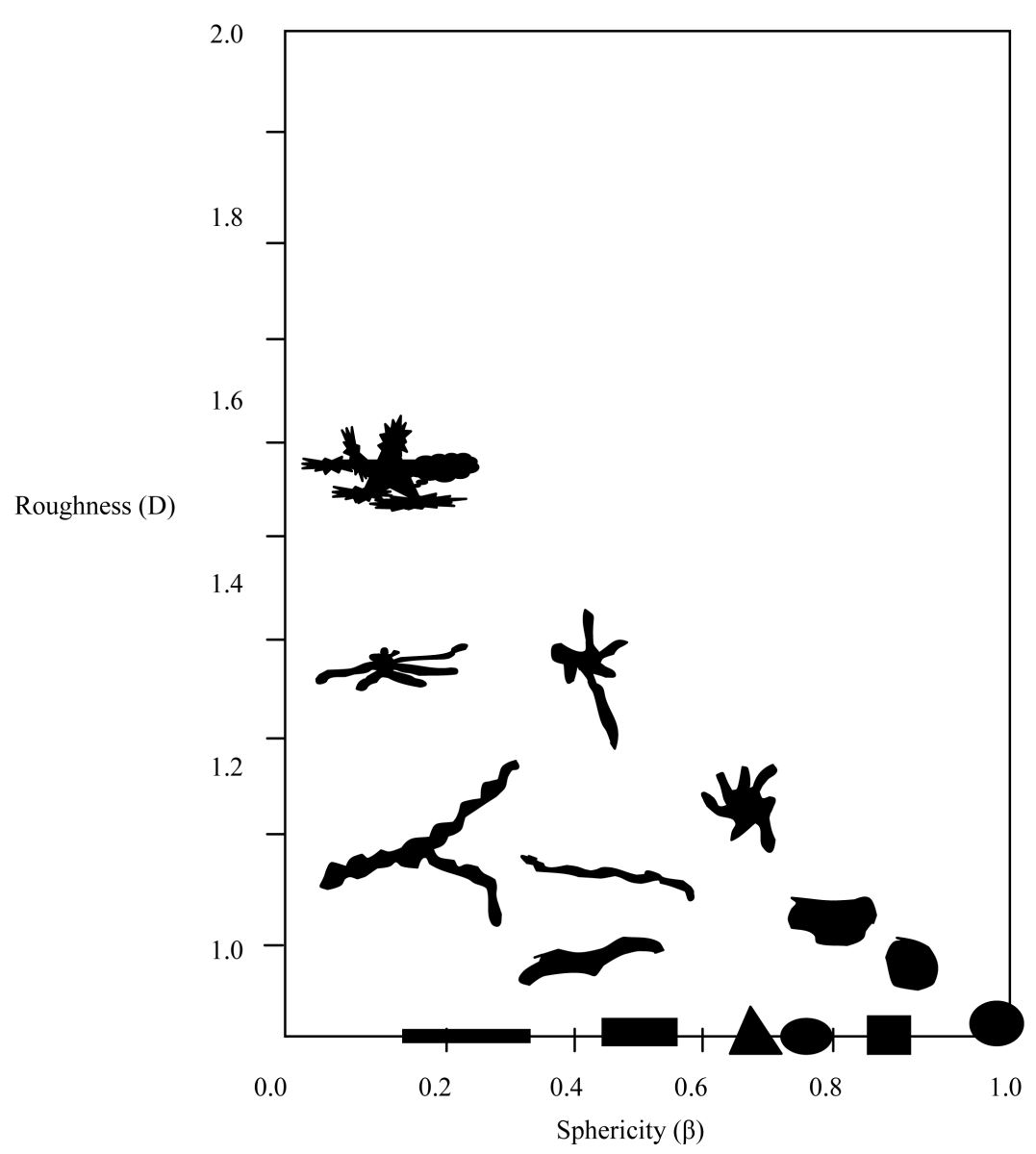

Figure 3. Illustration of development of irregular shapes based upon Euclidean circle or rectangle.

\section{Results and Discussion}

Presented in Figures 4(a)-(d) are the platelets distribution map for $\mathrm{Cu}-4 \% \mathrm{Sn}-5 \% \mathrm{P}$ samples homogenized for holding time of 20, 30, 40, 50 minutes and 1 hour respectively. Spheroidization of phosphides platelets within the micrograph appeared at 20 mins holding time up to 1 hour, Figure 1. The phosphide platelets undergone changes in shapes and sizes as delineated within the micrographs. In Figure 4, the platelets could not be characterized due to their low values of sphericities.

Figure 4(a) shows the platelets distribution map for sample homogenized for 20 mins holding time. Weighted average sphericity and fractal dimension values of 0.8792 and 1.1590 were obtained. The platelets are irregular in shapes, clustered and superimposed on random background.

Presented in Figure 4(b) is the platelets distribution map for sample homogenized for 30 mins holding time. Weighted average values of 0.3700 and 1.2610 for sphericity and fractal dimension were obtained. The platelets are said to be irregular in shapes, clustered and superimposed on random background.

Also presented in Figure 4(c) is the platelets distribution map for sample homogenized for 40 mins holding time. Weighted average sphericity and fractal dimension values of 0.6301 and 1.1751 were obtained. The platelets are tending towards being regular in shapes.

Presented in Figure 4(d) is the platelets distribution map for sample homogenized for 50 mins holding time. Weighted average values of 0.8312 and 1.2201 for sphericity and fractal dimension were obtained. The platelets are said to be randomly distributed.

Also shown in Figure 4(e) is the platelets distribution map for sample homogenized for 1 hour holding time. Weighted average sphericity and fractal dimension values of 0.9521 and 1.1408 were obtained. The platelets can be said to be regular and randomly distributed. 


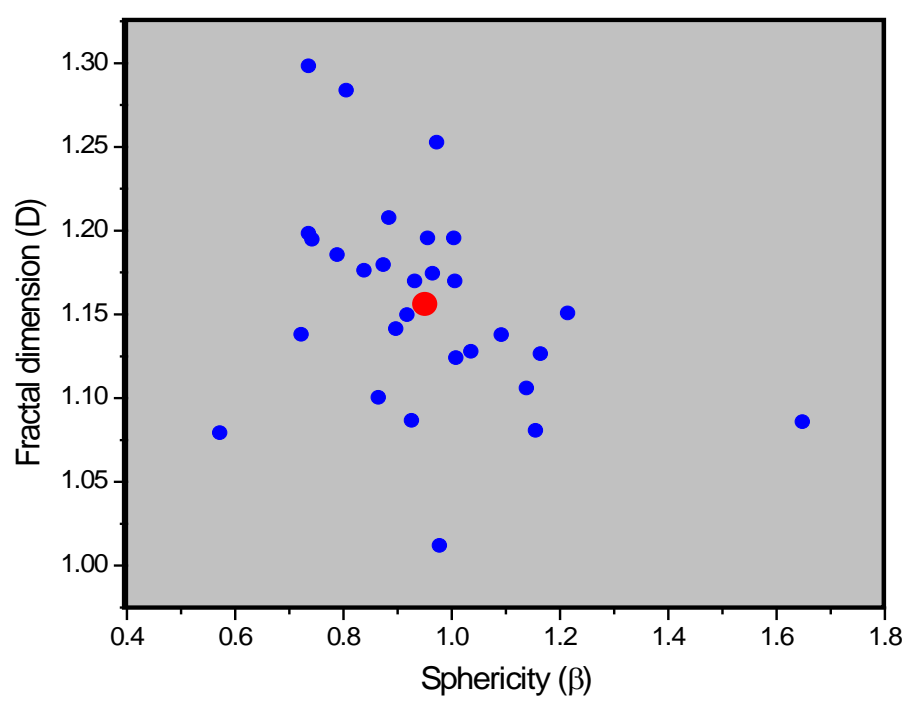

(a)

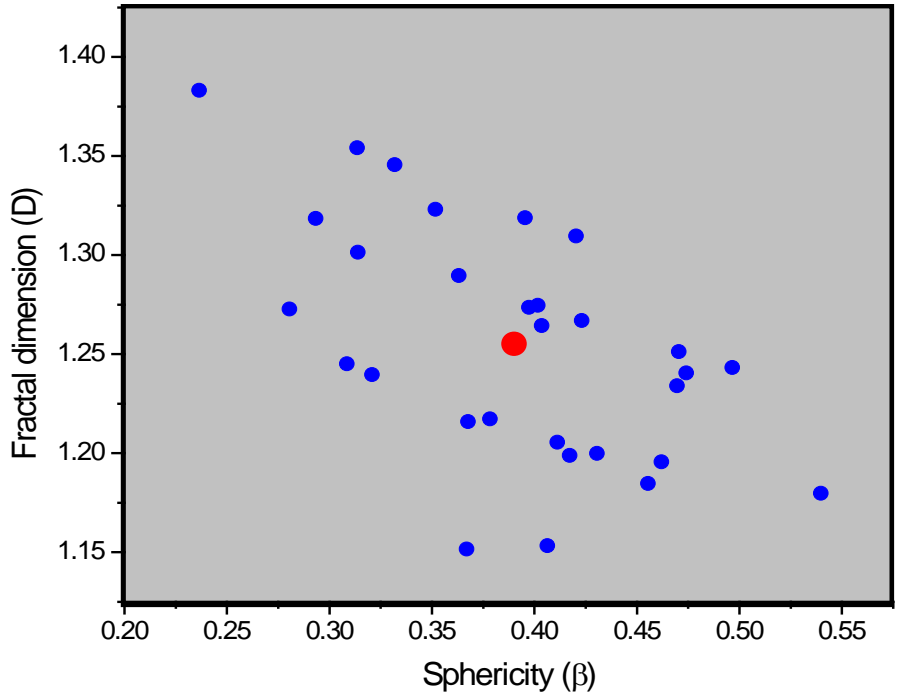

(b)

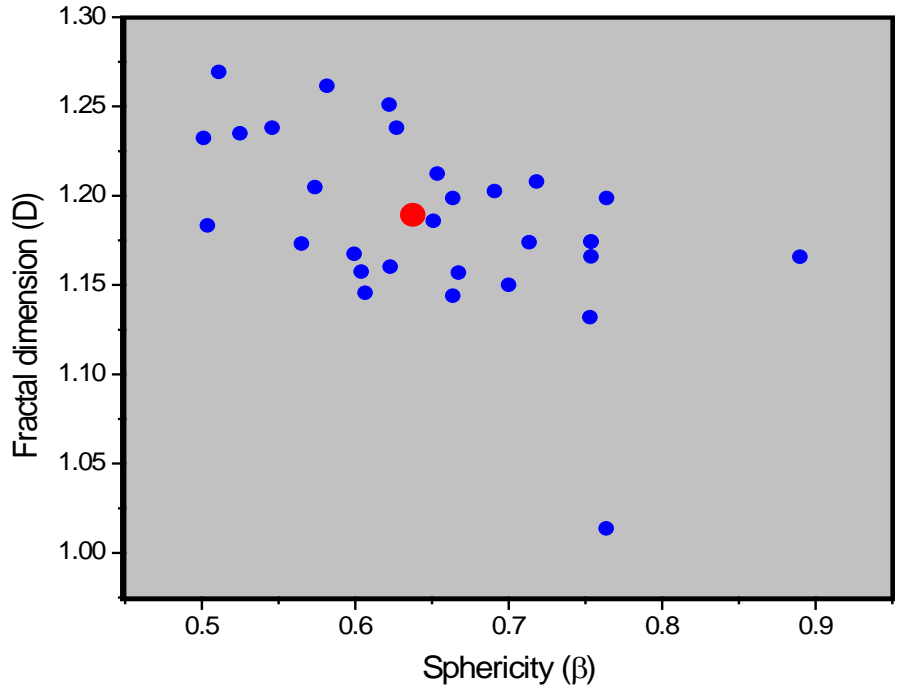

(c) 


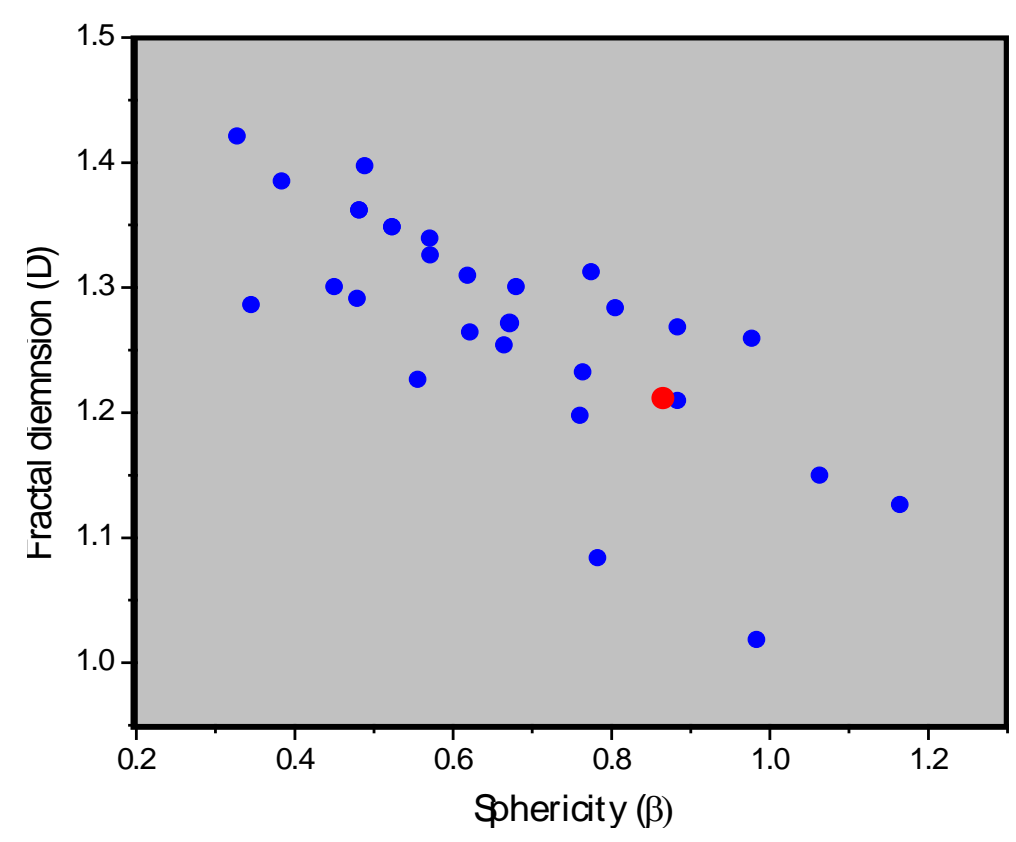

(d)

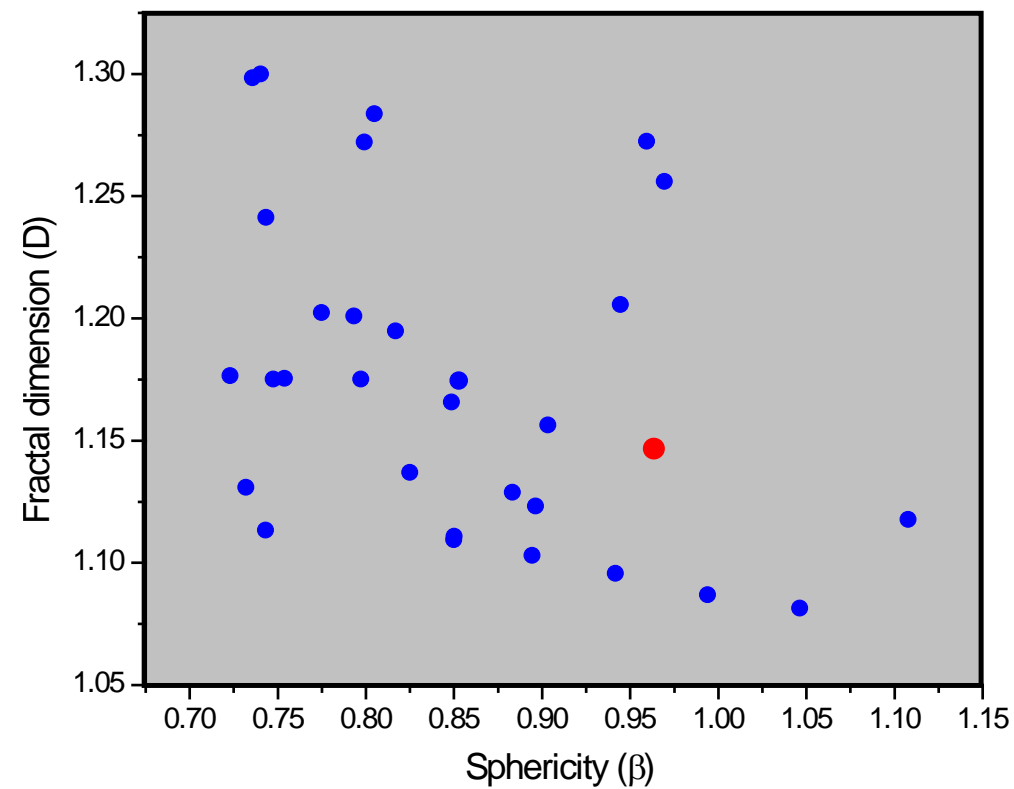

(e)

Figure 4. (a) Phosphide platelets distribution map for sample with 20 mins holding time; (b) Phosphide platelets distribution map for sample with 30 mins holding time; (c) Phosphide platelets distribution map for sample with 40 mins holding time; (d) Phosphide platelets distribution map for sample with 50 mins holding time; (e) Phosphide platelets distribution map for sample with 1 hour holding time.

\section{Conclusion}

From the platelets distribution maps, it can be seen that $\mathrm{Cu}-4 \% \mathrm{Sn}-5 \% \mathrm{P}$ samples homogenized for holding time of 50 mins and 1 hour produced phosphide platelets that are regular in shapes. Further increase in holding time may however favor the growth of phosphide platelets and the fractal dimension and sphericity may eventually reach the perfect shapes. 


\section{References}

[1] Kohler, F., Campanella, T., Nakanishi, S. and Rappaz, M. (2008) Application of Single Pan Thermal Analysis of Cu-Sn Peritectic Alloys. Acta Materialia, 56, 1519-1528. http://dx.doi.org/10.1016/j.actamat.2007.12.006

[2] Ozgowicz, W. (2012) Thermal Analysis of Vacancy Defects in Tin Bronzes— $\propto$. Journal of Achievements in Mechanical and Materials Engineering, 391-395.

[3] Brown, L. (1994) Cost-Effective Manufacturing: Joining of Copper and Copper Alloys. CDA Publication.

[4] Davis, J.R. (2001) Copper and Copper Alloy. ASM Specialty Handbook. ASM International, Materials Park, OH.

[5] Kuniteru, M., Tatsuhiko, E., Takashi, Y. and Akihiro, K. (2004) Effects of Metallographic Structures on the Properties of High-Performance Phosphor Bronze. Furukawa Review, 26, 44-48.

[6] Masota, W., Akihiko, I. and Hiromi, M. (2013) A Basic Study of Dynamic Recrystalization in Cu-Sn-P Alloy for High Strength Copper. Kobelco Technological Review, 31, 96-103.

[7] Durowoju, M.O. and Babatunde, I.A. (2013) The Effect of Varying the Composition of Phosphorus on the Microstructure and Mechanical Properties of Tin-Bronze Alloys. International Journal of Modern Engineering Research, 3, 1801-1804.

[8] Tuttle, J., Canavan, E. and DiPirro, M. (2009) Thermal and Electrical Conductivity Measurements of CDA 510 Phosphorus Bronze. Advance in Cryogenic Engineering, 52, 124-131.

[9] Woodcraft, A.L., Ventura, G., Martelli, V. and Holland, W.S. (2010) Thermal Conductance at Millikelvin Temperatures of Woven Ribbon Cable with Phosphorus-Bronze Clad Superconducting Wires. Advance in Cryogenic Engineering, 50, 465-468. http://dx.doi.org/10.1016/j.cryogenics.2010.06.001

[10] Andreas, L., Monika, G. and Wolfram, S. (2012) Experimental Investigation on the Ternary Phase Diagram Cu-Sn-P. World of Metallurgy-ERZMETALL, 2, 117-125.

[11] Kutz, M. (2002) Handbook of Materials Selection. John Wiley \& Sons, Inc., New York. http://dx.doi.org/10.1002/9780470172551

[12] Mandelbrot, B.B. (1983) The Fractal Geometry of Nature. Freeman Publishers, London.

[13] Durowoju, M.O. and Akintan, A.L. (2013) Variation between Fractal Geometry andMechanical Properties of Al Alloys under Different Heat Treatments. International Journal of Science and Advanced Technology, 3, 38-44.

[14] Hangai, Y. and Kitahara, S. (2008) Quantitative Evaluation of Porosity in Al Die Castings by Fractal Analysis of Perimeter. Materials Transactions, 49, 782-786. http://dx.doi.org/10.2320/matertrans.MRA2007314

[15] Huang, Y.J. and Lu, S.Z. (2002) A Measurement of the Porosity in Aluminum Cast Alloys Using Fractal Analysis. Proceeding of 2nd International Aluminum Casting Technology Symposium, Houston.

[16] Kong, J., Xu, C., Li, J., Chen, W. and Hou, H. (2011) Evolution of Fractal Features of Pores in Compacting and Sintering Process. Advanced Powder Technology, 22, 439-442. http://dx.doi.org/10.1016/j.apt.2010.06.012

[17] Lu, S.Z. and Hellawell, A. (1995) Fractal Analysis of Complex Microstructures in Materials. Proceedings of MC95 International Metallographic Conference, Colmar, 10-12 May 1995, 115-119. 